\title{
THE PRODROMAL SYMPTOMS OF INFAN'TILE PARALYSIS
}

\author{
BASED ON A STUDY OF 400 HistoRIES OF PATIENTS ADMITTED TO THF. \\ WILLARD PARKER HOSPITAL FROM JULY 1 TO \\ SEPTEMBER 1, 1916, INCLUSIVE * \\ MAY G. WILSON, M.D.
NEW YORK
}

These histories were obtained by personal interviews with parents, corroborated, when possible, by family physicians. Every effort was made to obtain an accurate history of the onset and course of the illness prior to admission. The wide publicity given this disease resulted in the early recognition and unusually close observation of the illness and symptoms of the child.

The symptoms included in this report were those noted from the onset of illness until the appearance of paralysis. Falls, overexertion, unusual excitement, overeating, and dentition preceding the onset were given as causes. The onset as a rule, was acute, attacking an apparently healthy child unawares.

I will take up the prominent prodromal symptoms in the following order: Fever, gastro-intestinal symptoms, respiratory symptoms, nervous symptoms, urinary system, skin.

Fever.-Fever was the most constant initial symptom, being noted in 334 cases. Only 2 per cent., on careful investigation, gave no history of fever, the temperature rapidly reaching its fastigium in twenty-four to forty-eight hours. The highest temperature noted was 106 degrees, the average, 103; duration, from one to ten days, average duration, four days, falling by crisis or lysis.

The following tabulation and Chart 1 show the relation of the duration of the fever to the day of the disease.

$\begin{array}{ccc}\text { Fever } & \text { Days } & \text { Cases } \\ 0 & \because & 8 \\ . . & 1 & 17 \\ . . & 2 & 45 \\ . . & 3 & 71 \\ . & 4 & 63 \\ . . & 5 & 39 \\ . . & 6 & 27 \\ . . & 7 & 21 \\ . . & 9 & 6 \\ . . & 10 & 2 \\ . . & 11 & 4\end{array}$

* Submitted for publication April 9, 1917.

* Read before the New York Academy of Medicine. Pediatric Section, Oct. 12. 1916 . 


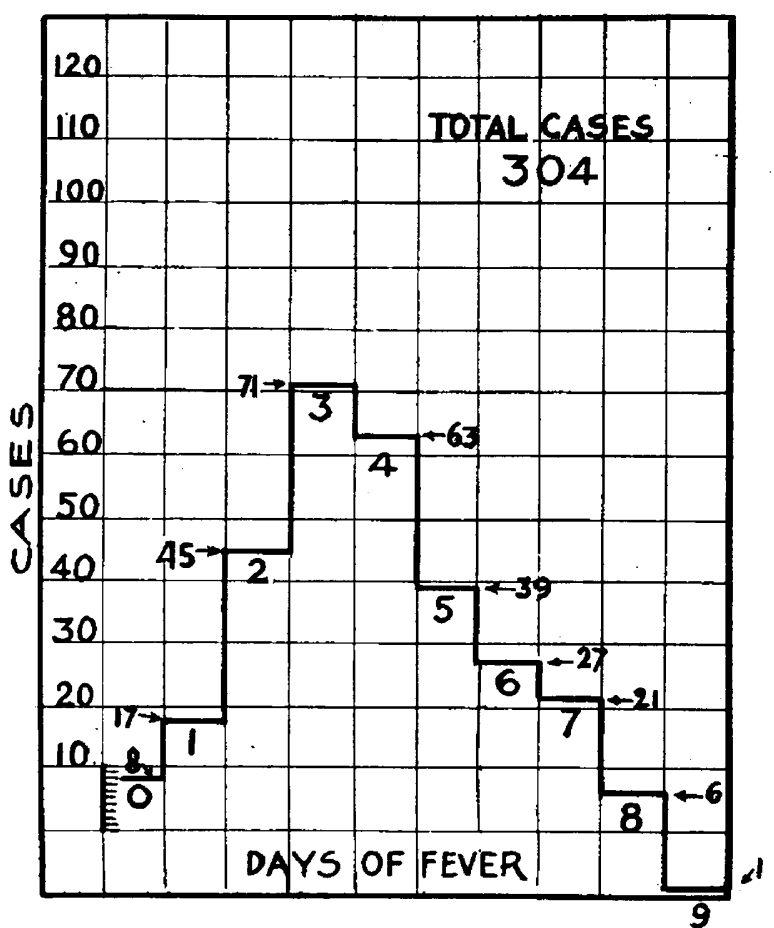

Chart 1.-Relation of duration of fever to day of disease.

In cases of remission or relapse, an initial fever of one or two days was followed by apparent health from two to six days, with a secondary fever, and ensuing paralysis.

The following tabulation and Chart 2 show the relation of the onset of paralysis to the day of the disease.

$\begin{array}{ccc}\text { Paralysis } & \text { Days } & \text { Cases } \\ 0 & \because & 6 \\ . . & 2 & 10 \\ . . & 2 & 67 \\ . . & 3 & 120 \\ . . & 4 & 79 \\ . . & 5 & 27 \\ . . & 7 & 12 \\ . . & 8 & 10 \\ & 9 & 1\end{array}$

Gastro-Intestinal Symptoms. - Vomiting: This was noted as an initial symptom in sixty-seven cases, as an early symptom in 132, sometimes occurring after the child had retired in apparently good health and slept a while; more usually, however, immediately on taking food. The vomiting was seldom repeated; in one instance it was of a projectile character.

Constipation: One hundred and fifty-six cases gave a definite history of persistent constipation for two or more days, resisting ordinary 
catharsis, and only relieved by repeated enemas. Fecal scybali were often found on examination.

Diarrhea: Diarrhea was not a common symptom in this series, being present in only twenty-five cases, and being neither severe nor characteristic. Abdominal pain was noted as an initial symptom in twenty-one cases, as an early symptom in twenty-five. When present, it was usually severe, persisting several days, referred to the epigastrium or general, and in two instances simulating appendicitis.

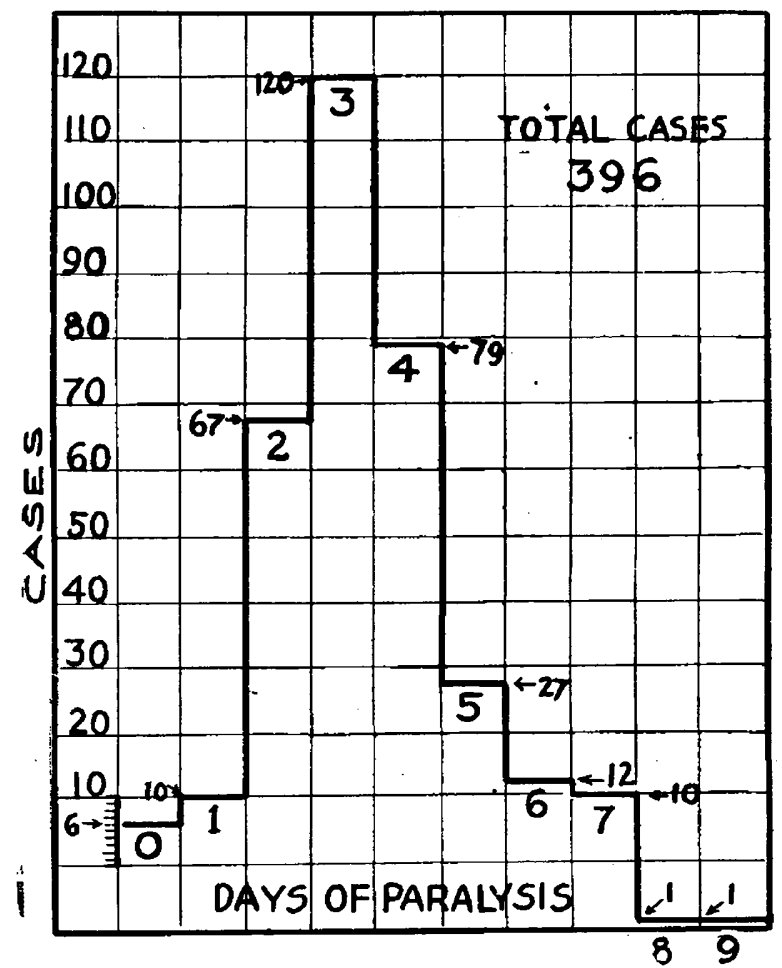

Chart 2.- The relation of the onset of paralysis to the day of the disease.

Respiratory Symptoms. - Throat: As an initial symptom, sore throat was complained of in 21 cases. A red throat was noted in 27 cases, follicular tonsillitis in 14 . On examination of 100 cases on admission, injected fauces were found in 31 cases, enlarged inflamed tonsils in 11 , exudate in 3 , mucopurulent, frothy discharge in 7 .

Epistaxis was present in two cases as an initial symptom.

Coryza was present in seventeen cases.

Conjuctivitis was present in nine cases.

Cough was present in thirty-eight cases, usually slight; two instances of severe bronchitis were noted. As a group, these symptoms were not common or characteristic. 
Nervous Symptoms. - Drowsiness: Persistent drowsiness was an early and characteristic symptom, noted in 288 cases; that is, 72 per cent., varying from slight apathy to stupor in forty-seven cases. As one mother stated: "The baby just wanted to sleep all the time, and I had to keep him awake to nurse him." It was of common occurrence in the admitting room to find children sound asleep and difficult to arouse, in spite of their strange surroundings and long ride in the ambulance.

Irritability was next in frequency, noted in 153 cases. Associated with this symptom was marked hyperesthesia, noted in ninety-seven cases, the slightest touch or even approach being resented. "My baby is sore all over," said a mother.

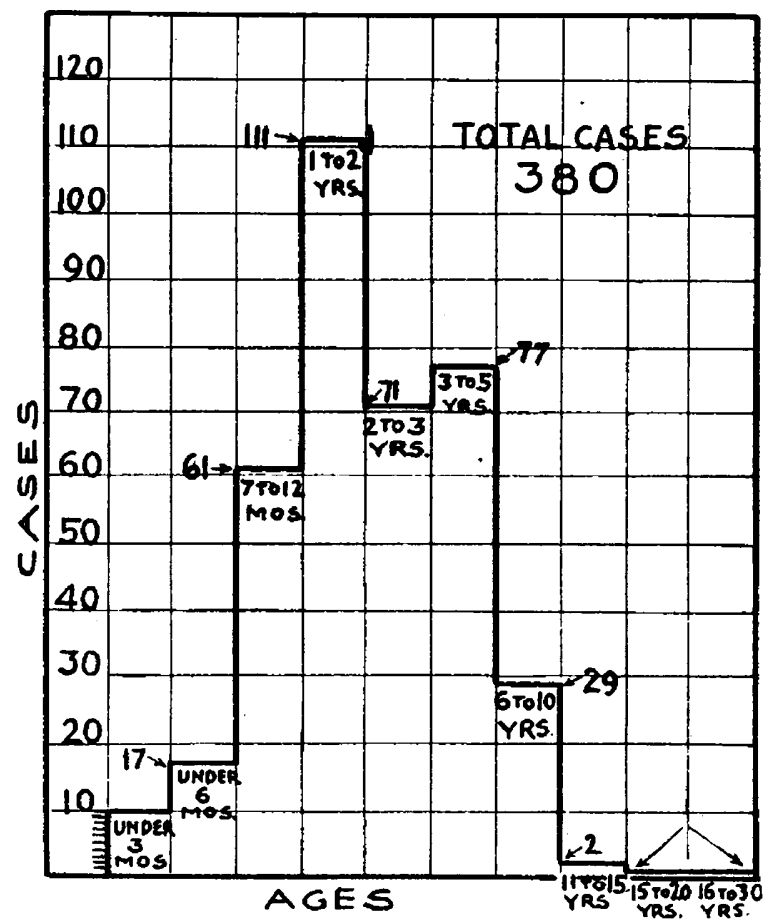

Chart 3.-Age incidence.

Tenderness and stiffness of the neck was an early and common symptom, noted in 161 cases. Retraction of the neck and flexion of the lower extremities appeared in forty cases.

Pain was present in 130 cases, usually referred to extremities, neck, back, shoulders and chest.

Tremor was noted in 113 cases, sometimes limited to a single muscle or group of muscles, usually of the extremities. Parents would remark: "Child seemed to shiver," or, "I first noticed when Mary took a piece 
of bread how her hands trembled like an old man's." Tremor persisted during the febrile period, preceding the paralysis by twenty-four to forty-eight hours. Two cases showed a marked, coarse tremor, persisting for several weeks, limited to one side of the body, resembling intention tremor, absent when asleep and recurring on the slightest irritation.

Twitching was noted in sixty-four cases, sometimes choreiform. Twitching of the corner of the mouth of ten preceded a facial paralysis.

Headache was present in seventy-eight cases, often persistent and severe; frontal or general headache was the first symptom complained

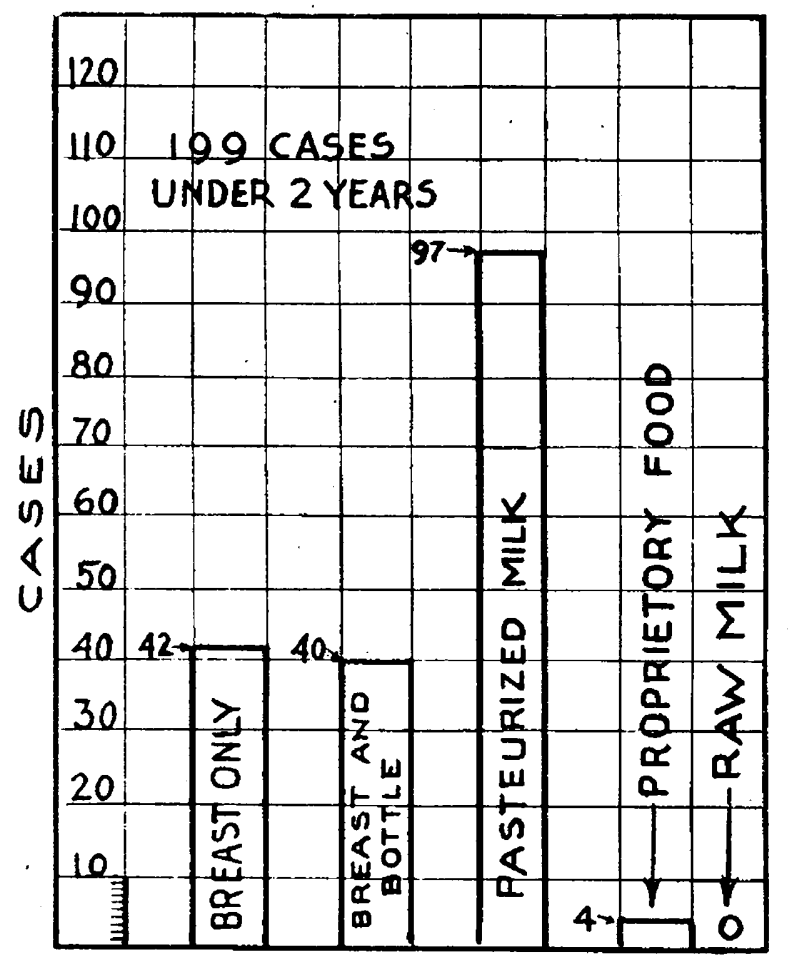

Chart 4.-Previous feeding.

of in twelve cases. Convulsions were present in six cases, as an initial symptom in three. Two cases were of children giving histories of previous convulsions.

Delirium was noted in ten cases.

Urinary System.-Twenty-one cases gave a history of some urinary disturbance, usually minor retention.

Skin.- There was noted profuse sweating in forty-five cases, and out of proportion to the fever present, usually preceding the paralysis. and as a rule, general; in a few instances, localized. 
Rash: Red blotches on extremities, 2 cases; general erythema, 4 cases; macular, resembling measles, 8 cases; urticaria, 4 cases; pustular, 2 cases; herpes, 7 cases, over back and trunk, and in one case limited to arm later paralyzed.

The clinical picture of the abortive type of the disease corresponds in general with the initial stage of a typical case followed by paralysis. Mild initial symptoms may be followed by extensive paralysis, and, on the other hand, cases with severe and alarming onset have shown slight paralysis and rapid recovery.

In this series the ages were (Chart 3 ):

Under 3 months, 10 .

3 to 5 years, 77 .

7 to 12 months, 61 .

6 to 10 years, 29 .

1 to 2 years, 111 .

11 to 15 years, 2 .

2 to 3 years, 71 .

16 to 30 years, 2 .

Sex: 222 males and 178 females.

The race incidence was as follows:

$\begin{array}{lll}\text { Hebrew, 152 } & \text { American, 76 } & \text { Italian, 70 } \\ \text { Irish, 50 } & \text { Polish, 17 } & \text { German, 6 } \\ \text { Colored, 6 } & \text { Swedish, 4 } & \text { Japanese, 1 }\end{array}$

Previous contagious diseases:

$\begin{array}{lll}\text { Measles, } 45 & \text { Scarlet fever, } 6 & \text { Diphtheria, } 4 \\ \text { Chickenpox, } 4 & \text { Whooping cough, } 7 & \end{array}$

Twelve cases had had recent operations on the tonsils, 8 had hypertrophied tonsils and 87 had normal tonsils.

Of 537 exposures in the families in which the disease occurred there were 50 secondary cases.

Of the previous feeding it was ascertained as follows (Chart 4):

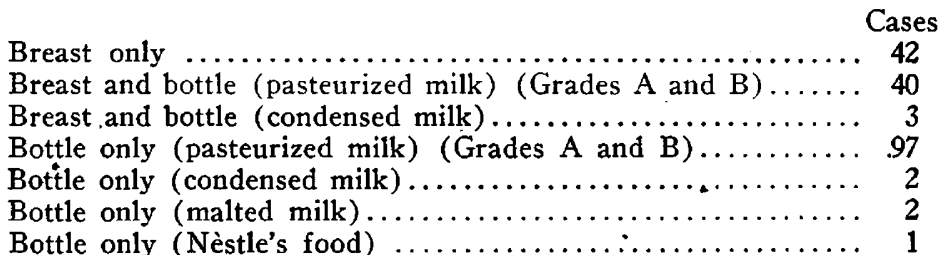

As to summer errors of diet, that is, ice cream, soda water, candy, pastries, watermelon, spoiled fruits, 163 out of a total of 292 children over 2 years old gave a history of over indulgence in this respect.

\section{REPCRT OF CASES}

The following case histories illustrate the various symptoms of onset:

CASE 1.-Girl, aged 27 months; onset, Saturday, August 12, with high fever. Vomited breakfast; increasing drowsiness; bowels constipated; twitching of the corner of the mouth. Sunday, a. m., twenty-four hours after onset, facial paralysis was noted. Monday, p. m., temperature normal; child well except for facial paralysis. Discharged October 14 with slight facial paralysis. 
CASE 2.-Girl, aged 71/2 years; onset, Thursday, July 27 , with severe frontal headache. Vomited breakfast; temperature 105. The child was extremely irritable, complained of pain in the extremities, stiffness of the neck and general twitching. Sunday, July 30 , the fourth day of the disease, paralysis of legs and arms was observed. Discharged October 1, with paralysis of legs and arms..

CASE 3.-Girl, aged $21 / 2$, sister of the patient, Case 2. Gave the following history: For the previous week the child complained of general malaise, headache and abdominal pain. July 31 , the child was up and about. August 1, took to bed with high fever, headache and abdominal pain. Vomited. August 3 and 4, became increasingly drowsy, going into coma, August 5. Admitted August 6, with temperature 103. August 17, normal temperature. Child fully recovered; no paralysis. Discharged October 1 .

CASE 4.-Boy, aged 3, one of twins. Onset Wednesday, August 10. Wednesday, August 10, the child was playing as usual, but spent a restless night with high fever. Thursday the child was unusually sleepy and remained in bed. The bowels were constipated; complained of headache, but did not seem ill. On Saturday morning, except for the bowels not moving, the child seemed much better. Saturday, p. m., there was a marked change; twitching of the hands, a sudden difficulty in breathing and rattling in the chest. The child was admitted to the hospital at $6 \mathrm{p} . \mathrm{m}$. and died in three hours of respiratory paralysis.

CASE 5.--Boy, one of twins, aged 20 months. (Brother died after three days' illness, July 9.) July 10, the patient had high fever, tonsillitis, constipation; child became increasingly drowsy; was irritable and did not want to be taken up. July 12 , admitted to hospital; sore throat, fever, drowsy. July 14, two days later, the child was well, but very weak. July 15 , third day, the child was apparently normal and was almost considered as a "no case" by one of the attending physicians who had not seen the child before.

CAse 6.-Boy, aged 20 months (brother, 3 years of age, died after an illness, July 10 to July 13 , of respiratory paralysis). Onset, July 17; first symptoms vomiting, fever, increasing drowsiness, profuse sweating. July 19, mother noticed the child could not lift the upper lids of both eyes. Admitted July 20; temperature 100.5 , pulse 110 , respiration 30 ; stuporous; erythematous rash over body. The only paralysis noted was that of both upper lids. July 26 , the child was standing in his crib, apparently well, but not being able to lift both eyelids.

CASE 7.-Woman, married, aged 28. Onset July 31 ; severe frontal headache. fever; vomited; had backache and abdominal pain and some cough. She thought she had caught cold. She took to bed August 1; sweat profusely, the symptoms of onset persisting. August 2, felt weakness in the right leg; by the next day it affected her left leg and she was unable to move it. August 3 , sharp pains in both lower extremities; especially painful to the touch in the course of the nerves. On admission, August 4, there was paralysis of both lower extremities.

Case 8.-Boy, aged $3 \frac{1}{2}$ years. Onset August 8. First symptom, headache; vomited. Was better the next day and was up and about. August 10 , he became apathetic; had projectile vomiting all day; complained of pain in the head. Became increasingly drowsy; could not stand or sit up; was very sensitive to touch; had some stiffness of the neck and back. Admitted August 11 ; temperature 101; stuporous; eyes did not coordinate; muscular weakness of right and left deltoid and right and left quadriceps extensors. All reflexes absent. The child was seen January 1 ; no residual paralysis.

CASE 9.-Girl, colored, aged 4 years. Onset August 6, with fever, difficulty in breathing, increasing drowsiness, obstinate constipation. On the second day, twitching of extremities; cried out with pain in the head; was very sensitive to touch and had some cough. On the third day, weakness of the right and left deltoid. Admission August 9; temperature 102, pulse 140, respiration 38; throat 
slightly congested; sensorium cloudy; paralysis of upper extremity and intercostals, with weakness of lower extremity; all reflexes exaggerated. The child died August 17 of respiratory paralysis.

CASE 10.-Boy, aged 7 years. Onset August 3; first symptoms, fever, vomiting, abdominal pain. Persistent headache; increasing drowsiness. August 6, patient became delirious and got out of bed. Admitted August 8. Throat congested; chest clear; abdomen tender and distended; sensorium cloudy; no definite paralysis noted; all reflexes exaggerated; spinal sign present. August 9, patient semistuporous; scaphoid abdomen; retention of urine. August 11, weakness of both deltoids; reflexes absent. August 12, general condition very much improved. August 13, paralysis of both deltoids. August 17, general condition normal; paralysis of both deltoids present.

CASE 11.-Girl, aged 7 years. Onset July 26, with fever; vomited several times; was extremely irritable and did not wish to be handled; complained of headache and pain in the throat. July 27, sweat profusely; was drowsy and voice became hoarse; had difficulty in swallowing. Admitted to the hospital, July 28 ; temperature 101 ; paralysis of the muscles of deglutition and laryngeal involvement. Died July 30.

\section{CONCLUSION}

The prodromal period has been found to be the most important stage in the course of the disease, both as to early quarantine and treatment. A careful history, while not diagnostic, is very suggestive, particularly in an epidemic.

I wish to express my thanks to the director, visiting and resident staff of the Willard Parker Hospital for the opportunity and cooperation afforded me in this study.

601 West 177th St. 